\title{
Laboratory-Scale Experiments of the Methane Hydrate Dissociation Process in a Porous Media and Numerical Study for the Estimation of Permeability in Methane Hydrate Reservoir
}

\author{
Yasuhide Sakamoto, ${ }^{1}$ Takeshi Komai, ${ }^{1}$ Kuniyuki Miyazaki, ${ }^{1}$ Norio Tenma, \\ Tsutomu Yamaguchi, ${ }^{2}$ and George Zyvoloski ${ }^{3}$ \\ ${ }^{1}$ National Institute of Advanced Industrial Science and Technology (AIST), Tsukuba, Ibaraki 305-8568, Japan \\ ${ }^{2}$ Department of Environmental Science, Faculty of Science, Toho University, Funabashi, Chiba 134-8540, Japan \\ ${ }^{3}$ Earth and Environmental Science Division, Los Alamos National Laboratory (LANL), Los Alamos, NM 87545, USA
}

Correspondence should be addressed to Yasuhide Sakamoto, sakamoto-yasuhide@aist.go.jp

Received 3 August 2009; Accepted 1 December 2009

Academic Editor: Costas Tsouris

Copyright ( 2010 Yasuhide Sakamoto et al. This is an open access article distributed under the Creative Commons Attribution License, which permits unrestricted use, distribution, and reproduction in any medium, provided the original work is properly cited.

\begin{abstract}
An experimental study of the dissociation of methane hydrate $(\mathrm{MH})$ by hot-water injection and depressurization was carried out at the National Institute of Advanced Industrial Science and Technology (AIST). These experiments helped us understand some important aspects of $\mathrm{MH}$ behavior such as how temperature, pressure, and permeability change during dissociation and gas production. In order to understand the experimental results, a model of $\mathrm{MH}$ dissociation in a porous media was designed and implemented in a numerical simulator. In the model, we treated the $\mathrm{MH}$ phase as a two-component system by representing the pore space occupied by $\mathrm{MH}$ as a separate component. Absolute permeability and relative permeability were formulated as a function of $\mathrm{MH}$ saturation, porosity, and sand grain diameter and introduced into the numerical model. Using the developed numerical simulator, we attempted history matching of laboratory-scale experiments of the $\mathrm{MH}$ dissociation process. It was found that numerical simulator was able to reproduce temperature change, permeability characteristics, and gas production behavior associated with both $\mathrm{MH}$ formation and dissociation.
\end{abstract}

\section{Introduction}

Methane hydrate $(\mathrm{MH})$ is an ice-like solid substance in which a water molecule structure contains embedded methane molecules under low-temperature and high-pressure conditions. When $1 \mathrm{~m}^{3}$ of $\mathrm{MH}$ is decomposed, approximately $150 \mathrm{~m}^{3}$ of methane gas is produced at standard conditions. In the near future, $\mathrm{MH}$ will be a potential resource of natural gas, because vast amounts of $\mathrm{MH}$ reservoirs exist in marine sediments and in permafrost regions worldwide [1-5] .

Some extraction methods of $\mathrm{MH}$ from reservoirs in marine sediments have been proposed, such as depressurization, thermal stimulation, and inhibitor injection (Makogon, 1981). All are based on the in-situ dissociation of MH that is transformed into methane gas and water. It is likely that this process consists of the following physical phenomena .
(1) The porosity and permeability of porous media are changed as a result of $\mathrm{MH}$ dissociation.

(2) Dissociated gas and water migrate through pore space, which is enlarged by the dissociation of $\mathrm{MH}$ crystals that has functioned as a binder between sand grains.

(3) The temperature and enthalpy are changed by the generation of heat and mass flows due to $\mathrm{MH}$ dissociation.

All the proposed extraction methods have drawbacks. In the thermal stimulation process, the thermal efficiency for injected fluid is low. Temperature losses in the drill pipe and heat conduction in the host rock and sediments severely limit the heat available for dissociation. In the inhibitor injection process, chemical materials used as inhibitors are costly and 
are of unproven value in marine environments. In addition, environmental risk due to utilization of such materials has not been evaluated. Therefore, depressurization process is regarded as the most effective process for gas recovery from the viewpoints of gas productivity, safety, and economical efficiency, compared with the other in-situ dissociation processes [6]. However, an increase in effective stress during depressurization can cause consolidation of $\mathrm{MH}$ sediments and permeability reduction [7]. As a result, reduction of gas productivity is likely over time with depressurization. Even though heat is not added during the depressurization process, the latent heat requirement for dissociation causes cooling and a reduction in dissociation rate. Therefore, it is very important to understand the behavior of an $\mathrm{MH}$ reservoir, especially during the extraction phase and when considering the environmental impacts due to reservoir operation .

In order to safely and efficiently design and operate an $\mathrm{MH}$ reservoir, it is necessary to develop a numerical simulator for prediction of gas productivity from an $\mathrm{MH}$ reservoir and carry out a parametric study for the optimization of gas production. Some numerical studies of $\mathrm{MH}$ dissociation in porous media have been reported. These studies are classified into (1) the analysis of the physical phenomena observed in laboratory-scale experiments, such as the movement of the $\mathrm{MH}$ dissociation front and the flow behavior of gas and water, and (2) field-scale simulations of a potential $\mathrm{MH}$ resource. Yousif et al. [8] developed a one-dimensional simulator for depressurization in Berea sandstone core and conducted an analysis of the $\mathrm{MH}$ saturation distribution and production behavior of gas and water and the movement of the dissociation front. Selim and Sloan [9] suggested a one-dimensional MH dissociation model for heat stimulation methods. They distinguished between the dissociated zone saturated with gas and water and the nondissociated zone and developed some analytical solutions. Jeannin et al. [10] investigated the dissolution of methane gas into the water phase and treated methane mole fraction in water as the driving force for dissociation in their simulation model. Holder and Angert [11] developed a three-dimensional simulator for depressurization intended for an $\mathrm{MH}$ reservoir located over a free-gas layer. Masuda et al. [12] developed a multidisciplinary field-scale simulator, including dissociation rate, endothermic reaction due to dissociation, mass flows and heat transfer and carried out a parameter study for the various gas extraction methods for an $\mathrm{MH}$ reservoir. Although the permeability of the $\mathrm{MH}$ reservoir is one of the most important parameters affecting the flow of gas and water during dissociation, and in predicting gas productivity, there is little research on the change in effective permeability with $\mathrm{MH}$ formation and dissociation. Therefore, it is necessary to develop a conceptual model for the change in permeability with $\mathrm{MH}$ formation and dissociation and implement this conceptual model into the numerical simulator.

We have performed laboratory-scale experiments on $\mathrm{MH}$ dissociation processes in porous media by hot-water injection and depressurization in order to understand several phenomena that occur during $\mathrm{MH}$ formation and dissociation. These include temperature and permeability changes, dissociation kinetics, and gas production behavior. On the basis of the experimental results, we constructed a numerical representation of $\mathrm{MH}$ dissociation in porous media. We also measured the absolute permeability and relative permeability with $\mathrm{MH}$ formation and formulated permeability as a function of $\mathrm{MH}$ saturation, porosity, and sand grain diameter. Using the developed numerical simulator, we attempted history matching of laboratoryscale experiments for $\mathrm{MH}$ dissociation process, validated the numerical model, and improved our understanding of the evolution of permeability during $\mathrm{MH}$ extraction.

\section{Experimental Evaluation of Permeability Characteristics during MH Dissociation Process in Porous Media}

Firstly, in order to understand permeability change and gaswater multiphase flow during $\mathrm{MH}$ dissociation process in porous media, we carried out an experimental study on hotwater injection as a way to enhance $\mathrm{MH}$ dissociation. In this study, we used several types of sand columns in which sand grains and water were packed into a high-pressure stainless steel vessel as model $\mathrm{MH}$ reservoirs. The internal diameter of the vessel is $65 \mathrm{~mm}$, and the length is $539 \mathrm{~mm}$. The experiment's pressure and temperature were limited to $15 \mathrm{MPa}$ and $50^{\circ} \mathrm{C}$, respectively. The vessel was set vertically, and the fluid was injected at the top edge and produced at the bottom edge of the vessel. On the basis of measured differential pressure between upper and lower edges of sand column, water effective permeability with $\mathrm{MH}$ formation was expressed as a multiplier of absolute permeability and relative gas, and liquid permeabilities were also calculated during $\mathrm{MH}$ dissociation. The details of the apparatus and experimental procedure have been published previously [13]. As an example of permeability change and gas production behavior during $\mathrm{MH}$ dissociation by hot-water injection, the results for injected water and dissociation pressure of $41^{\circ} \mathrm{C}$ and $10 \mathrm{MPa}$, respectively, are shown in Figure 1. The figure shows the changes in temperature distribution, differential pressure, water permeability, and production behavior of gas and water with time. From this figure, it was found that $\mathrm{MH}$ dissociation by hot-water injection consisted of four stages: (1) displacement of free methane gas due to water injection, (2) permeability reduction due to additional $\mathrm{MH}$ formation in the downstream zone, (3) $\mathrm{MH}$ dissociation due to hotwater injection, and (4) completion of the dissociation. In particular, the $\mathrm{MH}$ reformation and growth observed at the initial stage had large effect on the dissociation behavior and permeability characteristics. We also carried out an experimental study of the simultaneous injection process of nitrogen and hotwater [14] (Sakamoto et al., 2005). Nitrogen acts as an inhibitor; methanol and salts are other wellknown inhibitors. The same apparatus used for the hot water injection was also used to simultaneously inject nitrogen and hot-water. This was done to evaluate the mixtures ability to prevent permeability reduction due to $\mathrm{MH}$ reformation and growth and to promote additional $\mathrm{MH}$ dissociation. The 


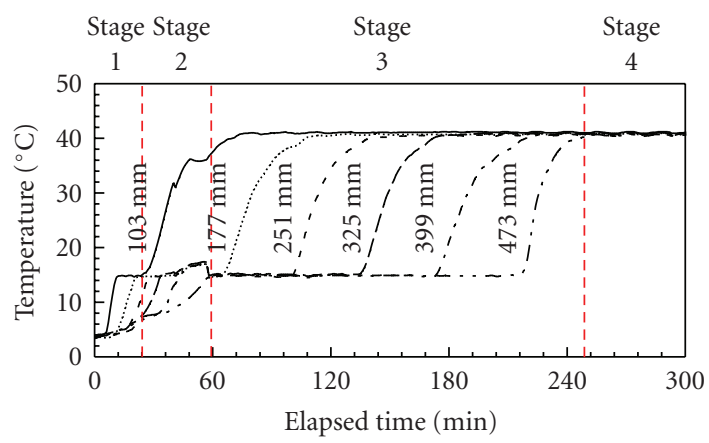

(a)

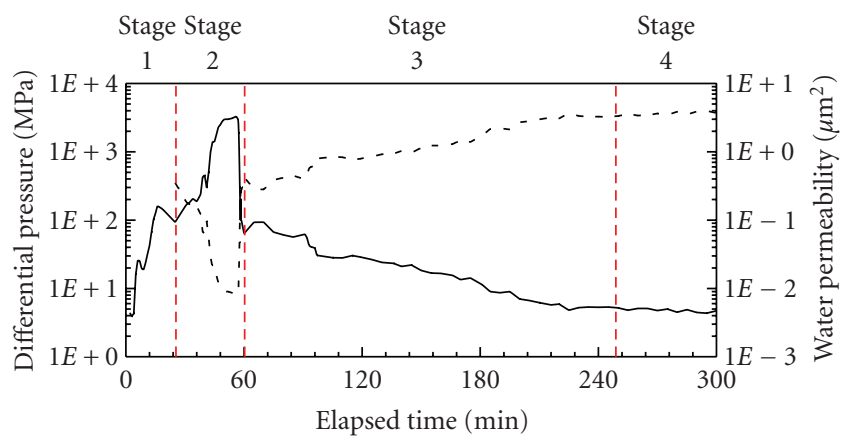

— Differential pressure - . Water permeability

(b)

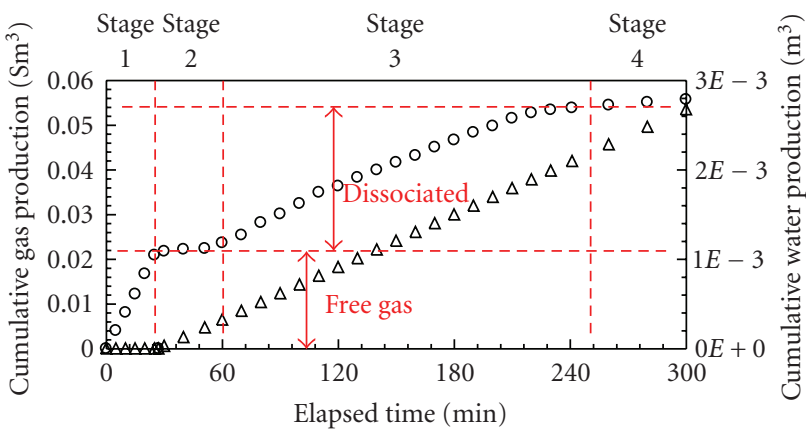

- Cumulative gas production

$\Delta$ Cumulative water production

(c)

FIGURE 1: Temperature and water permeability in sand column and gas production behavior in $\mathrm{MH}$ dissociation by hot-water injection: (a) temperature, (b) differential pressure and water permeability, and (c) cumulative production of gas and water.

nitrogen mixture is effective because the mole fraction of methane in the gas phase is reduced by injecting nitrogen and the equilibrium condition of $\mathrm{MH}$ is shifted to a lower temperature and higher pressure. Figure 2 shows the changes of water permeability with time during nitrogenhot-water simultaneous injection process. For comparison, the result of normal hot-water injection process as shown in Figure 1 was also plotted in Figure 2. As previously mentioned, permeability was significantly decreased due to $\mathrm{MH}$ reformation and growth in downstream zone of sand

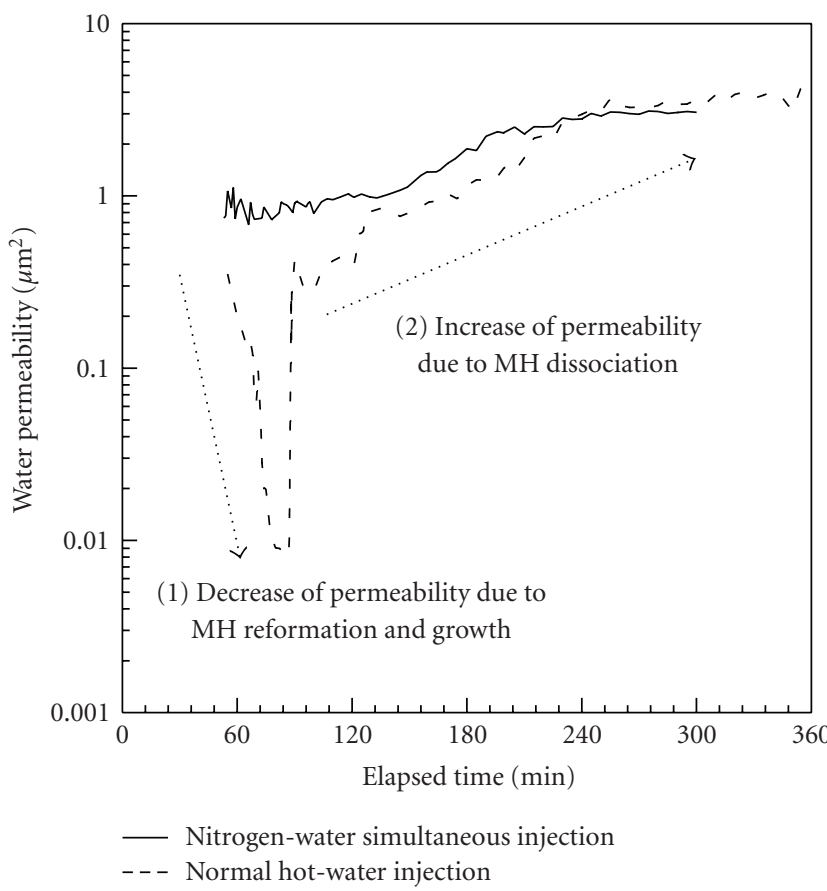

FIgure 2: Change of water permeability with time in the cases of nitrogen-water simultaneous injection and normal hot-water injection.

column at the early times with (only) hot-water injection. On the other hand, only a small permeability decrease with a gradual recovery was observed during the simultaneous injection process. In this experiment, $\mathrm{MH}$ is formed in the pore space by injecting high-pressure methane gas into the sand column under the condition of irreducible water saturation. Silica sand shows the tendency to water wet, so $\mathrm{MH}$ that existed before injection is treated as that formed on the surface of the sand grains. This $\mathrm{MH}$ derived from irreducible water decreases the effective flow path in the pore space depending on the irreducible water saturation. In this case, the permeability in a reservoir decreases gradually as $\mathrm{MH}$ saturation becomes higher, but plugging of pore space does not occur [15]. Therefore, it is probable that this significant permeability decrease observed in the case of only hot-water injection was due to the movement of dissociated gas and movable (injected) water reacting to reform $\mathrm{MH}$ in the pore space. This movable water is defined as "free water" as opposed to "irreducible water."

We also conducted laboratory-scale depressurization experiments to study permeability change due to reservoir consolidation. This is important because we expect some porosity change (and related permeability change) from mechanical compaction as result of $\mathrm{MH}$ dissociation and gas production. In order to develop models of porosity and permeability changes as a result of $\mathrm{MH}$ dissociation, pore changes from compaction must also be evaluated. A special type of apparatus was used to evaluate the horizontal permeability characteristics associated with vertical consolidation. The details of the apparatus and experimental procedure have been published in a previous paper [16]. The testing 
cell consisted of a stainless steel ring (internal diameter: $150 \mathrm{~mm}$, wall thickness: $100 \mathrm{~mm}$, and maximum pressure: $15 \mathrm{MPa}$ ) and upper and bottom plates for pressurization. In order to simulate MH sediments, we used several types of sands. An axial load that simulated rock stress conditions in marine sediments was applied on the upper edge of the sand pack using a loading piston. In order to initiate $\mathrm{MH}$ dissociation, the pore pressure was decreased at the center of the sand pack with a back-pressure regulator. Dissociation pressure and initial total stress by axial loading were set to $3 \mathrm{MPa}$ and $11 \mathrm{MPa}$, respectively. We used the following two conditions to evaluate consolidation behavior due to the change in effective stress. In Run No.1, pore pressure decreased from 10 to $3 \mathrm{MPa}$ while maintaining an axial load of $11 \mathrm{MPa}$. In this case, effective stress increased from 1 to $8 \mathrm{MPa}$ with depressurization. On the other hand, the effective stress during $\mathrm{MH}$ dissociation in Run No.2 was maintained at $1 \mathrm{MPa}$ in spite of the pore pressure change. Figure 3 shows the dependence of effective stress on the consolidation behavior during depressurization. When the effective stress reached $8 \mathrm{MPa}$ with depressurization, marked consolidation occurred in Run No.1. Then, consolidation gradually proceeded. The compressive strain, which is the amount of consolidation divided by the initial height of the sand pack, ultimately reached $1.47 \times 10^{-2}$. However, the strain after 2 minutes was $0.97 \times 10^{-2}$. Therefore, at the initial stage in which the effective stress was increased, the amount of consolidation was approximately $65.7 \%$ of the final value. On the other hand, the compressive strain in Run No.2 was maintained at a small value as the $\mathrm{MH}$ dissociation proceeded. From these results, we concluded that the volumetric change in the solid material due to $\mathrm{MH}$ dissociation was small. Therefore, the increase in the effective stress is a dominant factor for the consolidation behavior, and most of the consolidation occurs at the initial stage of depressurization. It is particularly important to predict permeability change at this stage, because of dissociated gas and water flow into the region where $\mathrm{MH}$ dissociation has already occurred. Therefore we estimated the effect of porosity reduction due to consolidation on permeability independently from changes of $\mathrm{MH}$ dissociation and formation.

\section{Development of Numerical Model for MH Dissociation Process in a Porous Media and Experimental Estimation of Permeability with MH Formation}

3.1. Modeling Pore Space Occupied by MH. To develop a numerical model for $\mathrm{MH}$ dissociation process in porous media, it is necessary to model the pore space occupied by of $\mathrm{MH}$. On the basis of observations of permeability characteristics in the laboratory studies, we defined two components of $\mathrm{MH}$ in pore space. Figure 4 shows the conceptual model of $\mathrm{MH}$ phase that exists in the pore space. One MH component $\left(S_{h 1}\right)$ is derived from irreducible water. This is formed as a cover on the surface of a sand grain, and it is assumed that the effect on the permeability

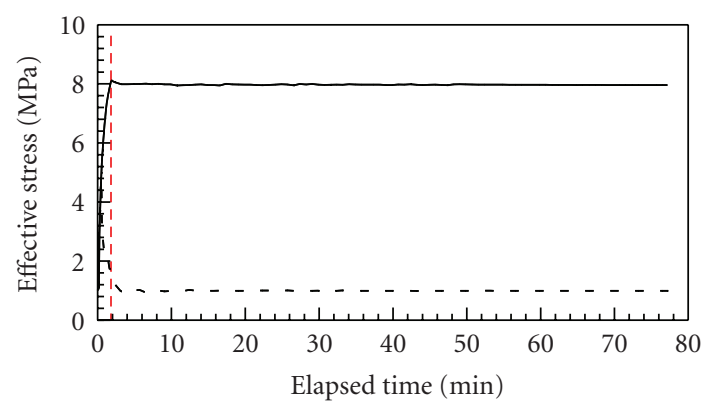

(a)

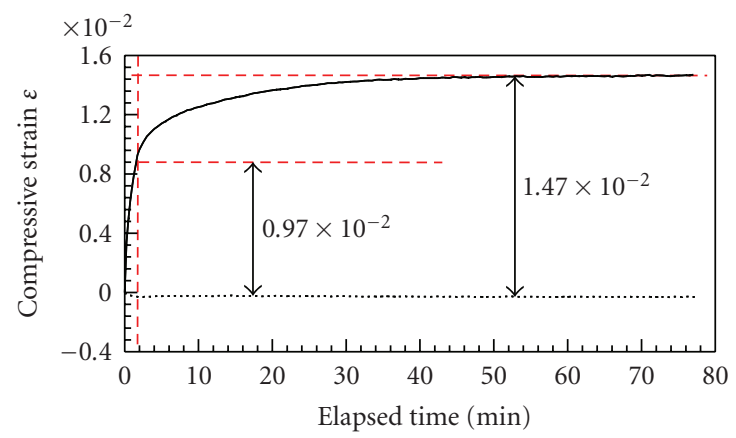

(b)

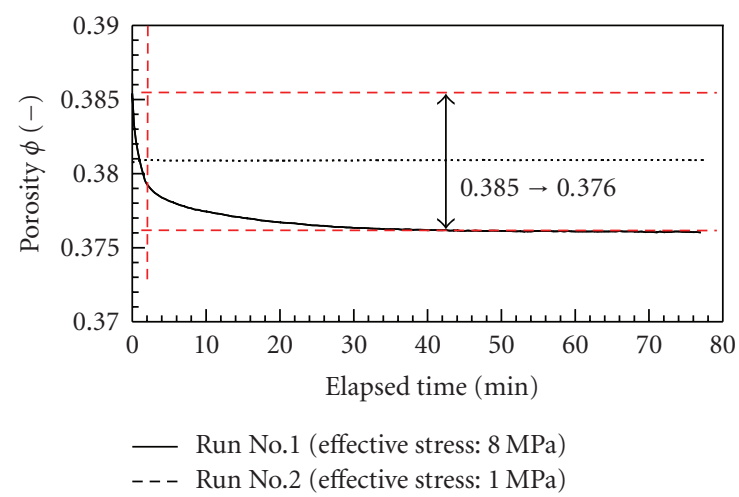

(c)

Figure 3: Consolidation behavior during MH dissociation in different effective stress case.

characteristics is small. This $\mathrm{MH}$ component exists under the initial experimental conditions. The other $\mathrm{MH}$ component $\left(S_{h 2}\right)$ is derived from moveable free water. The MH derived from free water is formed inside the pore space and generally plugs the flow path. It has a marked effect on permeability as observed in the experiments. In our conceptual model, the $\mathrm{MH}$ growth or formation rate is associated only with $\mathrm{MH}$ saturation $S_{h 2}$ derived from free water. The MH saturation $S_{h 1}$ derived from irreducible water does not change with time when temperature and pressure conditions are such that $\mathrm{MH}$ should form. In addition, we assume that the dissociation of $\mathrm{MH}$ derived from free water is preferentially started, because this $\mathrm{MH}$ exists in the neighborhood of a flow path and the heat available from injected water is preferentially supplied to this component. 


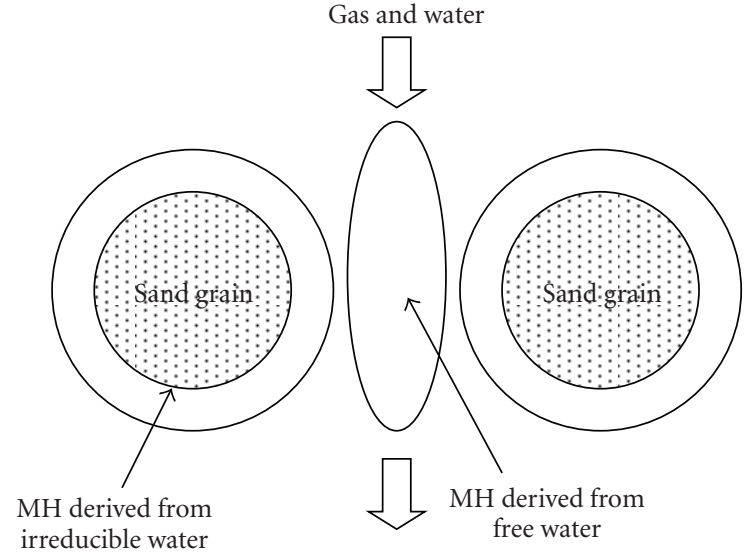

FIgURE 4: Schematic of MH two-component system.

The numerical model consists of a three-phase fourcomponent system: gas, water, $\mathrm{MH}$ derived from irreducible water, and $\mathrm{MH}$ derived from free water.

\subsection{Governing Equation in Porous Media with MH Formation}

3.2.1. Mass Conservation Equation. We assumed that $\mathrm{MH}$ does not have mobility, because it is a solid material. Therefore, we defined gas-water two-phase flow in the pore space along with $\mathrm{MH}$ formation and dissociation. The flow of gas and water is governed by Darcy's law. The mass conservation equations of gas, water, and $\mathrm{MH}$ are expressed by the following equations.

Is phaseis expressed as

$$
\nabla \cdot\left(\frac{K k_{r g} \rho_{g}}{\mu_{g}} \cdot \nabla \Phi_{g}\right)+\left(R_{d}\right)+\left(-R_{f}\right)=\frac{\partial\left(\phi \rho_{g} S_{g}\right)}{\partial t} .
$$

Water phase is expressed as

$$
\nabla \cdot\left(\frac{K k_{r w} \rho_{w}}{\mu_{w}} \cdot \nabla \Phi_{w}\right)+\left(N_{h} R_{d}\right)+\left(-N_{h} R_{f}\right)=\frac{\partial\left(\phi \rho_{w} S_{w}\right)}{\partial t} .
$$

$\mathrm{MH}$ derived from irreducible water is expressed as

$$
\left(-R_{d 1}\right)=\frac{\partial\left(\phi \rho_{h} S_{h 1}\right)}{\partial t} .
$$

$\mathrm{MH}$ derived from free water is expressed as

$$
\left(-R_{d 2}\right)+\left(+R_{f}\right)=\frac{\partial\left(\phi \rho_{h} S_{h 2}\right)}{\partial t} .
$$

Here, we have $R_{d}$ : total dissociation rate of $\mathrm{MH}, R_{d 1}$ : dissociation rate of $\mathrm{MH}$ derived from irreducible water, and $R_{d 2}$ : dissociation rate of $\mathrm{MH}$ derived from free water. Other symbols are defined in the SYMBOL table. The dissociation rates are related by the following equation:

$$
R_{d}=R_{d 1}+R_{d 2}
$$

3.2.2. Energy Conservation Equation. Energy is transferred by convection and conduction. $\mathrm{MH}$ formation latent heat was assumed to be the same value as that in the dissociation process and of opposite sign:

$$
\begin{gathered}
\nabla \cdot\left(\frac{K k_{r g} h_{g} \rho_{g}}{\mu_{g}} \cdot \nabla \Phi_{g}\right)+\nabla \cdot\left(\frac{K k_{r w} h_{w} \rho_{w}}{\mu_{w}} \cdot \nabla \Phi_{w}\right) \\
+\nabla \cdot\left(\lambda_{c} \cdot \nabla T\right)+\left(-H_{d} R_{d}\right)+\left(H_{d} R_{f}\right) \\
=\frac{\partial\left(\phi \rho_{g} S_{g} U_{g}+\phi \rho_{h} S_{h} U_{h}+\phi \rho_{w} S_{w} U_{w}+U_{r}\right)}{\partial t} .
\end{gathered}
$$

3.2.3. Equation of State. Simple equations of state (linear functions) were used to relate the density, enthalpy, and viscosities of the methane and water. The volume fractions (saturations) of all liquid and gas phases and hydrate fraction add to unity:

$$
S_{g}+S_{h}+S_{w}=1 .
$$

The total MH saturation $S_{h}$ is expressed as follows:

$$
S_{h}=S_{h 1}+S_{h 2} .
$$

The basic variables in this model are flow potential: $\Phi_{g}, \Phi_{w}$, saturation of each phase: $S_{g}, S_{w}, S_{h 1}, S_{h 2}$, and temperature $T$.

3.3. Formulation for Permeability with $M H$ Formation. It is impossible to experimentally estimate the effect of $\mathrm{MH}$ derived from free water on permeability changes. Therefore, we obtained a series of parameters for $\mathrm{MH}$ derived from irreducible water experimentally and extended the permeability equations as a function of $\mathrm{MH}$ (fraction) to a two-component system. The procedures of formulation permeability have already been described in our previous papers $[17,18]$.

3.3.1. Absolute Permeability K. We firstly measured water effective permeability $K_{w}$ under pressure and temperature conditions in which $\mathrm{MH}$ has formed from residual water and gas saturations. Three types of sand columns (Toyoura sand, No.7 silica sand, and No.8 silica sand) were used for measurement of $K_{w}$. In this study, we assumed that relative permeability to water $k_{r w}$ under the residual gas saturation condition was constant and independent of MH saturation. Therefore, it is possible to estimate $K$ with $\mathrm{MH}$ formation by dividing the measured $K_{w}$ by $k_{r w}$ as follows:

$$
K=\frac{K_{w}}{k_{r w}} .
$$

We obtained the result that the relative permeability in the case of an $\mathrm{MH}$ saturation of 0.4 was 0.03 compared with the original values without any $\mathrm{MH}$ present. This tendency was common and independent of kinds of used sand. Based on the experimental results, we formulated the absolute permeability $K$ as a function of $\mathrm{MH}$ fraction, $S_{h 1}$. We selected the equation proposed by Masuda et al. [12]. In 
(10), the parameters $N_{1}$ (called the reduction factor) and $K$ (permeability) are functions of $S_{h 1}$, the irreducible hydrate fraction. $K_{0}$ is the original permeability value of sand column without any $\mathrm{MH}$ formation:

$$
\begin{aligned}
K & =K_{0} \cdot\left(1-S_{h 1}\right)^{N_{1}} \\
N_{1} & =10.384 \cdot S_{h 1}^{2}-27.773 \cdot S_{h 1}+13.639
\end{aligned}
$$

The absolute permeability $K$ in the $\mathrm{MH}$ two-component system is expressed as follows. In this model, setting the reduction factor $N_{2}$ for $S_{h 2}$ to be smaller value than $N_{1}$ for $S_{h 1}$, it is possible to reproduce the extreme permeability reduction observed in the experiments:

$$
\begin{aligned}
& K=K_{0} \cdot\left(1-S_{h}\right)^{N_{1}} \quad\left(S_{h} \leq S_{h 1 \max }\right), \\
& K=K_{0} \cdot\left(1-S_{h 1 \max }\right)^{N_{1}} \cdot\left(\frac{1-S_{h}}{1-S_{h 1 \max }}\right)^{N_{2}} \quad\left(S_{h}>S_{h 1 \max }\right) .
\end{aligned}
$$

Figure 5 shows the dependence of $\mathrm{MH}$ saturation on absolute permeability. The value of $K$ at maximamal value $S_{h 1 \text { max }}$ of $S_{h 1}$ decreases significantly as $S_{h 2}$ becomes higher as shown in this figure. Furthermore, when whole pore space is occupied by $\mathrm{MH}\left(S_{h 1}+S_{h 2}=S_{h}=1\right), K$ takes on the limiting value of 0 .

The change in absolute permeability $K$ from porosity change due to consolidation was considered. As previously mentioned, we found that effective stress was more important that than $\mathrm{MH}$ of dissociation when investigating consolidation. Therefore the effect of porosity reduction due to consolidation on permeability change could be independently estimated. The effect of porosity changes on permeability was expressed as a function of the ratio to initial porosity $\left(\phi / \phi_{0}\right),(13)$. By combining this equation with (12), we obtained (14) as

$$
\begin{aligned}
& K_{0}^{\prime}=K_{0} \cdot\left(\frac{\phi}{\phi_{0}}\right)^{N_{\phi}} \\
& K=K_{0} \cdot\left(\frac{\phi}{\phi_{0}}\right)^{N_{\phi}} \cdot\left(1-S_{h 1 \max }\right)^{N_{1}} \cdot\left(\frac{1-S_{h}}{1-S_{h 1 \max }}\right)^{N_{2}} .
\end{aligned}
$$

We used the same apparatus that was used for depressurization experiments and obtained the change in permeability as a function of the porosity ratio $\left(\phi / \phi_{0}\right)$ experimentally by conducting consolidation-permeability tests with water that was injected into water-saturated samples. Figure 6 showed the dependence of effective stress on change in axial displacement and change of differential pressure with time during consolidation-permeability test in the case of No.8 silica sand. In this experiment, the rate of axial loading was set to a constant value of $0.141 \mathrm{MPa} / \mathrm{min}$. Differential pressure was gradually increased from $0.500 \mathrm{kPa}$ to $1.90 \mathrm{kPa}$ with time depending on reduction of porosity. Increase in differential pressure indicated a reduction of permeability in the pore space. By changing the initial porosity and sand

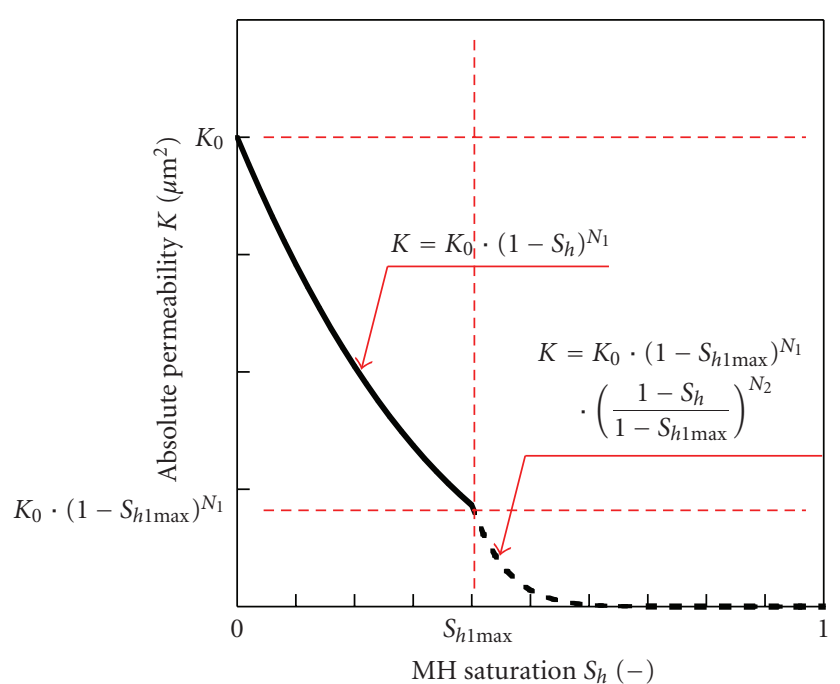

FIGURE 5: Formulation of absolute permeability as function of $\mathrm{MH}$ saturation in $\mathrm{MH}$ two-component system.

types, we obtained data which included differential pressure and deformation behavior due to consolidation with time.

The reduction factor $N_{\phi}$ in (14) was estimated numerical model calibration. The numerical simulator COTHMA (Coupled thermo-hydro-mechanical analysis with dissociation and formation of methane hydrate in deformation of multiphase porous media), developed by the West Japan Engineering Consultants, Inc., under MH21 Research Consortium, was used. We estimated the increment of displacement and pore pressure for each node in the numerical grid by using the stress-strain relationship obtained in consolidation-permeability tests. In addition, history matching using differential pressure data due to consolidation was carried out by varying the reduction factor $N_{\phi}$. The solid line and dashed one in Figure 6 show the results for the calculation. From this figure, calculation results could reproduce the changes of axial displacement and differential pressure. We only varied the reduction factor $N_{\phi}$ in numerical analysis, so this value represents permeability change due to consolidation. For all the simulations, the values of $N_{\phi}$ changed from 4.80 to 10.0 . We observed the following trends for $N_{\phi}$ : (1) $N_{\phi}$ became small in the case of large sand grain diameters. (2) $N_{\phi}$ became larger in the case of large initial porosity. Therefore, in this study, $N_{\phi}$ was formulated as a function of sand grain diameter $D_{A}$ and initial porosity $\phi_{0}$. The derived equation for $N_{\phi}$ is expressed as follows. As basic condition for formulation, we treated sand grain diameter $D_{A T}: 200 \mu \mathrm{m}$, initial porosity $\phi_{T 0}: 0.412$, and reduction factor $N_{\phi T}: 5.50$ in the case of Toyoura sand as

$$
N_{\phi}=a_{\phi} \cdot\left(\frac{D_{A}}{D_{A T}}-1\right)+c_{\phi} \cdot\left(\frac{\phi_{0}}{\phi_{T 0}}\right)+d_{\phi} \text {. }
$$

Here, $a_{\phi}=-3.96, c_{\phi}=8.55$, and $d_{\phi}=-2.86$. By introducing (15) into (14), it is possible to consider absolute permeability changes not only from $\mathrm{MH}$ dissociation but also from porosity changes due to consolidation. 


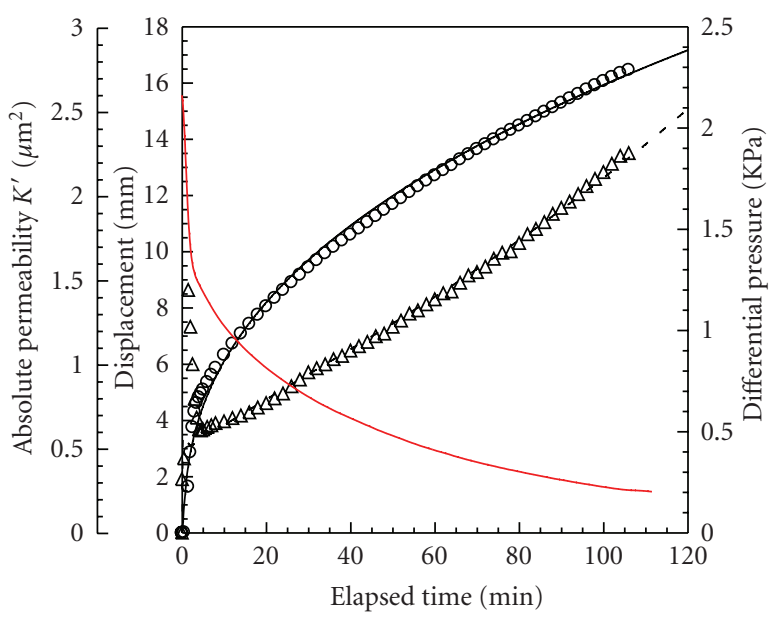

- Displacement: experimental

_ Displacement: calculation

$\Delta$ Differential pressure: experimental

- - - Differential pressure: calculation

_ Absolute permeability

Figure 6: Dependence of effective stress on change of axial displacement and change of differential pressure with time during consolidation-permeability test.

3.4. Irreducible Water Saturation $S_{w i}$ and Residual Gas Saturation $S_{g r}$. Irreducible water saturation $S_{w i}$ and residual gas saturation $S_{g r}$ are very important parameters in order to define the active saturation interval in gas-water multiphase flow for the relative permeability curves used in predicting the amount of dissociated gas. We assumed that the distribution of sand grain constituting real $\mathrm{MH}$ sediments is wide ranging and reservoir temperature changes with time due to $\mathrm{MH}$ dissociation and hot-water injection. Therefore it is important to estimate the effect of these parameters on flow behavior quantitatively in addition to $\mathrm{MH}$ saturation. In this study, we formulated $S_{w i}$ and $S_{g r}$ on the basis of the experimental results of the displacement of free methane gas by cold-water injection.

First of all, we used three types of sand, Toyoura sand, No.7 silica sand, and No.8 silica sand, and considered the effect of average sand grain diameter on changes of $S_{w i 00}$, the average residual water saturation, and $S_{g r 00}$, the average residual gas saturation, without any $\mathrm{MH}$ formation. $S_{\text {wion }}$ and $S_{g r 00}$ are formulated as functions of $D_{A} / D_{A T}$, on the basis of $S_{w i T}$ and $S_{g r T}$ of Toyoura measured without any $\mathrm{MH}$ formation at $4^{\circ} \mathrm{C}$ as follows:

$$
\begin{aligned}
& S_{w i 00}=S_{w i T}+\left(1 .-S_{w i T}\right) \cdot\left(1 .-\frac{D_{A}}{D_{A T}}\right)^{N w}, \\
& S_{g r 00}=S_{g r T} \cdot\left(\frac{D_{A}}{D_{A T}}\right)^{N g} .
\end{aligned}
$$

Then, $S_{w i 0}$ and $S_{g r 0}$ were formulated as a function of $\mathrm{MH}$ saturations $S_{h 1}$ and $S_{h 2}$, in order to extend (16) to account for the presence of $\mathrm{MH}$. It was experimentally observed that if the injection of methane gas was continued after $\mathrm{MH}$ formation, then additional water was not observed.
Therefore, the difference between the amount of irreducible water under the initial condition and the consumption of water for $\mathrm{MH}$ formation corresponds to the amount of irreducible water with $\mathrm{MH}$ formation. Figure $7(\mathrm{a})$ shows the changes in $S_{w i 0}$ as functions of $\mathrm{MH}$ saturation $S_{h 1}$ derived from irreducible water. As $S_{h 1}$ increased, $S_{w i 0}$ decreased markedly. $S_{w i 0}$ changed from 0.324 to 0.116 with $\mathrm{MH}$ saturation. $S_{w i 0}$ is expressed as a function of only $S_{h 1}$, using $S_{\text {wio0 }}$ previously formulated as (17) and the volume ratio $R_{V h w}$ of $\mathrm{MH}$ to water:

$$
S_{w i 0}=S_{w i 00}-R_{v h w} S_{h 1} .
$$

On the other hand, $S_{g r}$ ranged from 0.350 to 0.119 and showed a tendency to decrease with increasing $\mathrm{MH}$ saturation as shown in Figure 7(b). $S_{g r 0}$ is a function of $S_{h 1}, S_{h 2}$, and $R_{V h w}$. When all of the pore space was filled with $\mathrm{MH}$, $S_{g r 0}$ should become zero. These behaviors are represented by (18):

$$
\begin{aligned}
S_{g r 0}= & S_{g r 00} \cdot\left(1-S_{h 1}\right)^{N s g r 1} \\
& \cdot\left[\frac{1-S_{w i 00}-\left(1-R_{V h w}\right) \cdot S_{h 1}-S_{h 2}}{1-S_{w i 00}-\left(1-R_{V h w}\right) \cdot S_{h 1}}\right]^{N s g r 2} .
\end{aligned}
$$

Finally, we obtained the following final form of equations for $S_{w i}$ and $S_{g r}$ by extending (17) and (18) as a function of temperature $T$ :

$$
\begin{aligned}
& S_{w i}=S_{w i 0} \cdot\left[a_{s w i} \cdot\left(T-T_{0}\right)^{2}+b_{s w i} \cdot\left(T-T_{0}\right)+c_{s w i}\right]^{D_{A} / D_{A T}}, \\
& S_{g r}=S_{g r 0} \cdot\left[a_{s g r} \cdot\left(T-T_{0}\right)^{2}+b_{s g r} \cdot\left(T-T_{0}\right)+c_{s g r}\right]^{D_{A} / D_{A T}} .
\end{aligned}
$$

3.5. Relative Permeabilities $k_{r g}, k_{r w}$. Using parameters for gas-water multiphase flow, such as $S_{w i}$ and $S_{g r}$, we formulated the gas and water relative permeabilities $k_{r g}$ and $k_{r w}$, respectively, when $\mathrm{MH}$ is present. In our numerical model, we extended the interval of water saturation $S_{w}$ in the gas-water multiphase flow with the normalized water saturation $S_{w}^{*}$. Using $S_{w}^{*}$, we were able to use one set of relative permeability curves for any $\mathrm{MH}$ saturation condition:

$$
S_{w}^{*}=\frac{S_{w}-S_{w i}}{1-S_{g r}-S_{w i}-\left(S_{h 1}+S_{h 2}\right)}=\frac{S_{w}-S_{w i}}{1-S_{g r}-S_{w i}-S_{h}} .
$$

The Corey model that is used as a general relative permeability curve is expressed as follows. Here, $a$ and $b$ are the values of $k_{r g}$ and $k_{r w}$ at endpoints on the relative permeability curves. The endpoints are defined as the saturation conditions of $S_{w i}$ and $S_{g r}$. In addition, the limitations that (1) $k_{r g}$ was set to 1 in the case of $S_{w}=0$ and (2) $k_{r w}$ was set to 1 in the case of $S_{g}=0$ were adapted in this relative permeability model. The gas and liquid relative permeabilities are shown in (21):

$$
\begin{aligned}
& k_{r g}=a \cdot\left(1-S_{w}^{*}\right)^{2}\left\lfloor 1-\left(S_{w}^{*}\right)^{2}\right\rfloor, \\
& k_{r w}=b \cdot\left(S_{w}^{*}\right)^{4} .
\end{aligned}
$$




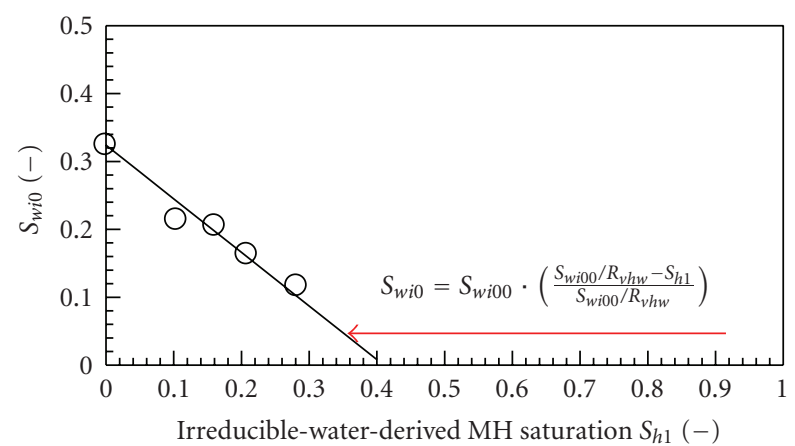

Irreducible-water saturation

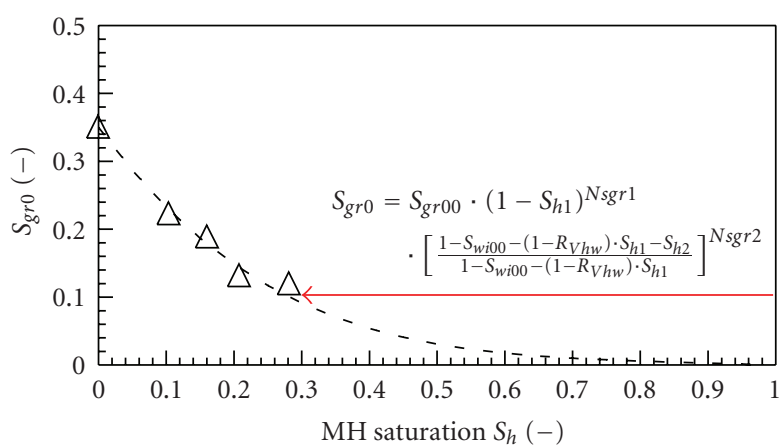

$\triangle$ Residual gas saturation

(a)

(b)

FIGURE 7: Formulation of irreducible-water saturation and residual gas saturation as functions of MH saturation in MH two-component system.

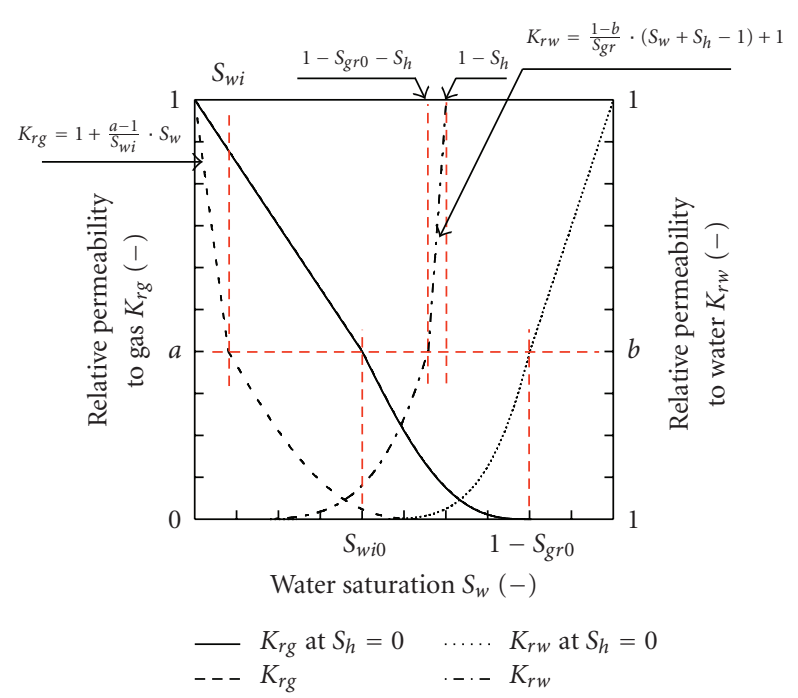

FIGURE 8: Relative permeability curves for different MH saturation conditions.

Figure 8 shows relative permeability curves for different $\mathrm{MH}$ saturation conditions. Both $k_{r g}$ and $k_{r w}$ changed with water saturation $S_{w}$ and $\mathrm{MH}$ saturation $S_{h}$ as shown in the figure. As $\mathrm{MH}$ saturation became higher, the curves were shifted to lower-water-saturation conditions.

\section{Numerical Simulation of Laboratory-Scale Experiments for MH Dissociation Process in a Porous Media and Optimization of Permeability Parameters with MH Formation}

To validate the numerical model and the developed permeability relationships with $\mathrm{MH}$ formation, we carried out numerical simulations of some of the previously mentioned laboratory-scale experiments for $\mathrm{MH}$ dissociation by hotwater injection and depressurization and compared the simulation results with experimental results. In this study, the simulation code FEHM (Finite Element Heat and Mass Transfer), developed at the Los Alamos National Laboratory, was used for calculations $[19,20]$. In the FEHM code, the conservation equations of energy and mass in a porous media are solved using the control volume finite element method. This code has some advantages for the multicomponent multiphase analysis and phase transformation analysis of $\mathrm{MH}$ formation and many permeability models. Originally, this code was developed for the analysis of the geothermal reservoirs. Using the model for $\mathrm{MH}$ dissociation process in a porous media as previously mentioned, we modified the FEHM code to include a one-component $\mathrm{MH}$ dissociation and formation, a two-component $\mathrm{MH}$ dissociation and formation, and a three-phase three-component system that represents gas, water, and $\mathrm{MH}[21]$.

4.1. Hot-Water Injection. In numerical simulation for hotwater injection process, we verified the validity of $\mathrm{MH}$ two-component model constructed in this study. Figure 9 shows a comparison of the experimental and calculation results for change in differential pressure and gas production behavior during $\mathrm{MH}$ dissociation by hot-water injection after extending the $\mathrm{MH}$ phase into two components in the simulator. "Two components" in the explanatory note shows the results in the case of $\mathrm{MH}$ two-component model developed in this study. For comparison, the results in $\mathrm{MH}$ one-component model are also shown in the same figure. "One component: No growth" is the case that $\mathrm{MH}$ growth (or $\mathrm{MH}$ formation) was not considered. $\mathrm{MH}$ growth was considered in the case of "One component: Growth." The change in differential pressure observed in the experiment consists of the following three stages: (1) an increase dependent on viscosity difference between gas and water, (2) a large increase as a result of $\mathrm{MH}$ formation in the downstream zone in the sand column, and (3) a permeability decrease as a result of $\mathrm{MH}$ dissociation. By introducing $\mathrm{MH}$ twocomponent model into the simulator, the calculation results sufficiently agreed with the experimental results. In regards to gas production behavior, the calculation also reproduced the series of behaviors observed in the experiment that 


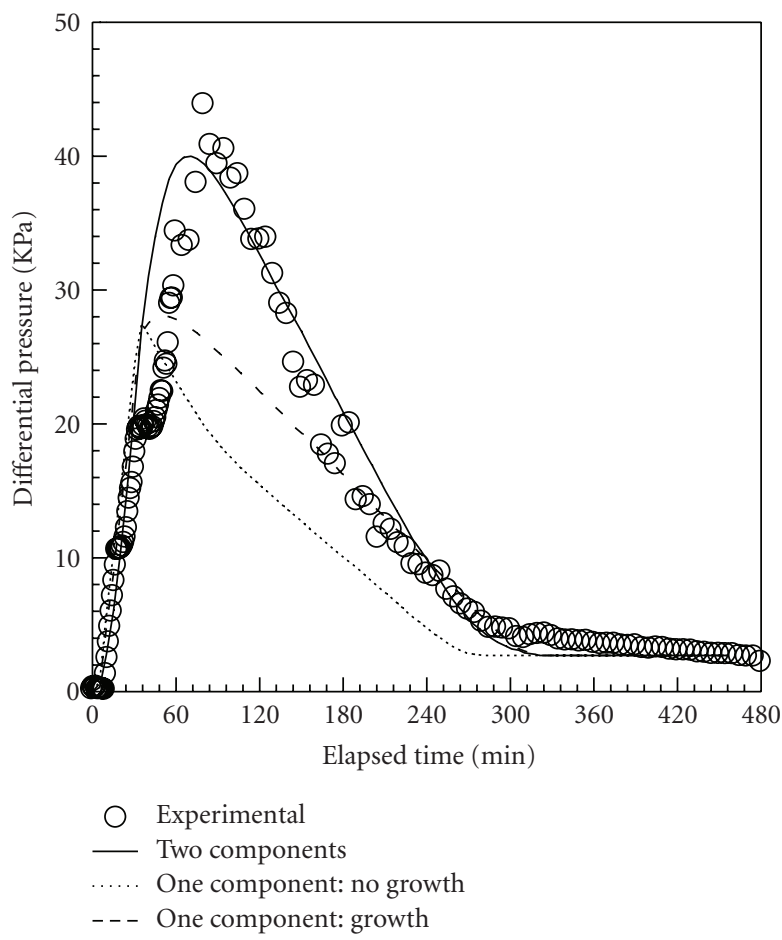

(a)

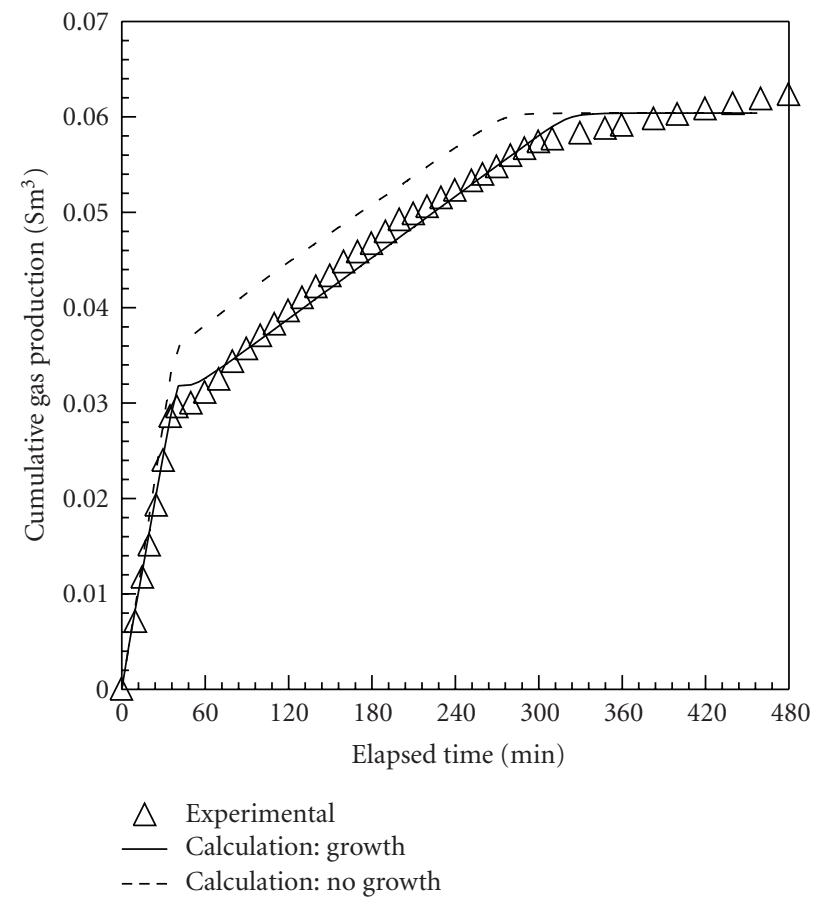

(b)

FIGURE 9: Comparison of experimental and calculation results for change in differential pressure and gas production behavior during MH dissociation by hot-water injection after extending the $\mathrm{MH}$ phase into two components.

consisted of (1) displacement of free methane gas, (2) delay of gas production due to $\mathrm{MH}$ growth, and (3) dissociated gas production. By comparing simulation and experimental results, it was found that the numerical simulator was able to reproduce temperature change, permeability characteristics, and gas production behavior, associated with both $\mathrm{MH}$ formation and dissociation.

4.2. Depressurization. MH dissociation that occurs in depressurization is strongly affected by two thermal processes: (1) latent heat release of MH in sediments and (2) thermal conduction from the surrounding area [22]. In addition, water saturation in pore space at the initial stage is relatively high. As a result, production behavior is accompanied by water displacement induced gas expansion from the pressure decrease and dissociated gas flow. Therefore thermal conductivity and relative permeability in gas-water multiphase flow system are dominant factors on $\mathrm{MH}$ dissociation and production behavior. Capillary pressure under the existence of $\mathrm{MH}$ is not well known, so we treat the pressure of each phase as identical system pressure in our numerical model. In this study, considering the difference of mobility between gas and water, we tried to reproduce production behavior observed in experiments by optimizing the shape of relative permeability curves. Changes in irreducible water saturation and residual gas saturation due to difference of sand grain size and dissociation are reflected in the relative permeability by the use of the normalized water saturation,
(20). Here, as an example of numerical simulation, we present the results of history matching in the case of No.8 silica sand (average sand grain diameter: $115 \mu \mathrm{m}$ ).

As previously mentioned, $\mathrm{MH}$ dissociation after a pressure decrease reaches an equilibrium condition limited by thermal conduction from surrounding material. Therefore, preliminary to the consideration of gas-water flow, we carried out history matching of the temperature change in sand column by varying the thermal conductivity of sediment. Yamamoto et al. [23, 24] considered the thermal conductivity $\lambda c$ of sedimentary layers containing $\mathrm{MH}$ using the mixture sample of sand and $\mathrm{MH}$. As a result, they observed that $\lambda c$ ranged from about 0.40 to $2.00 \mathrm{~W} /(\mathrm{m} \cdot \mathrm{K})$ depending on the amount of $\mathrm{MH}$ and saturation condition of gas and water. This value depended strongly on the types of sedimentary structure that were formed by the sand and $\mathrm{MH}$. The final result of the formulation for $\lambda c$ has not yet been reported. Therefore, we varied $\lambda c$ within the reported values and estimated the value of $\lambda c$ by comparison with temperature change in the experiments. Figure 10 shows the calculation results for temperature change during the $\mathrm{MH}$ dissociation by depressurization. It is generally known that thermal conductivity becomes smaller when gas instead of water fills the pore space. In the calculations, when $\lambda c$ was set to $1.06 \mathrm{~W} /(\mathrm{m} \cdot \mathrm{K})$, it was found that the change in the temperature distribution was such that (1) a temperature decrease from initial temperature of $11.7^{\circ} \mathrm{C}$ to an equilibrium condition of $1.70^{\circ} \mathrm{C}$ was observed with 


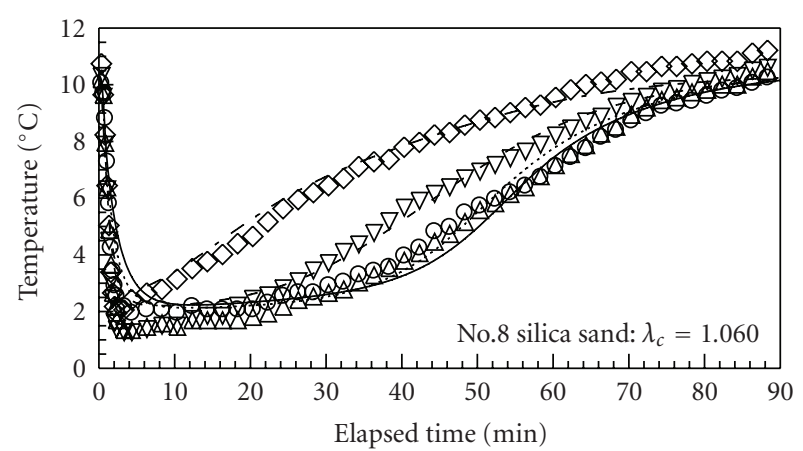

$$
\begin{array}{llll}
\circ & 2.5 \mathrm{~cm} \text { : experimental } & - & 2.5 \mathrm{~cm} \text { : calculation } \\
\triangle & 3.75 \mathrm{~cm} \text { : experimental } & \ldots . & 3.75 \mathrm{~cm} \text { : calculation } \\
\nabla & 5 \mathrm{~cm} \text { : experimental } & --- & 5 \mathrm{~cm} \text { : calculation } \\
\diamond & 6.25 \mathrm{~cm} \text { : experimental } & \ldots- & 6.25 \mathrm{~cm} \text { : calculation }
\end{array}
$$

Figure 10: Comparison of experimental and calculation results for temperature change with time during $\mathrm{MH}$ dissociation by depressurization (No.8 silica sand).

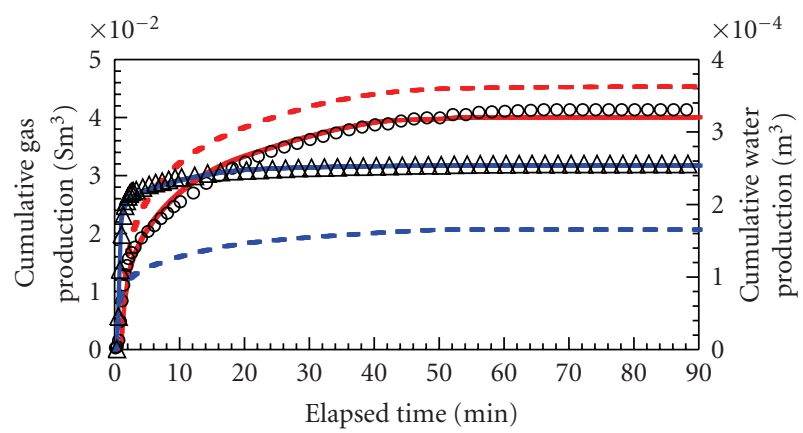

○ Gas: experimental

- - - Gas: calculation (Corey model)

_ Gas: calculation (extended linear model)

$\triangle$ Water: experimental

- - Water: calculation (Corey model)

— Water: calculation (extended linear model)

Figure 11: Comparison of experimental and calculated results for cumulative productions of gas and water when the different relative permeability curves were used (No.8 silica sand).

depressurization, and (2) a temperature increase to the outer boundary temperature after completion of dissociation could be sufficiently reproduced.

Then, we calibrated the gas-water relative permeability curves with $\mathrm{MH}$ present through history matching of production behavior during $\mathrm{MH}$ dissociation by depressurization. In these experiments, the permeability is relatively high even if solid $\mathrm{MH}$ exists in the pore space. Additionally, the effect of consolidation on the gas production behavior was not very large. Therefore, it is assumed that the most dominant parameter on the production behavior is relative permeability. We carried out history matching by using the Corey model expressed as in (21). Figure 11 shows the comparison of the experimental and calculated results for cumulative productions of gas and water when the Corey model was used for the relative permeability curves. From

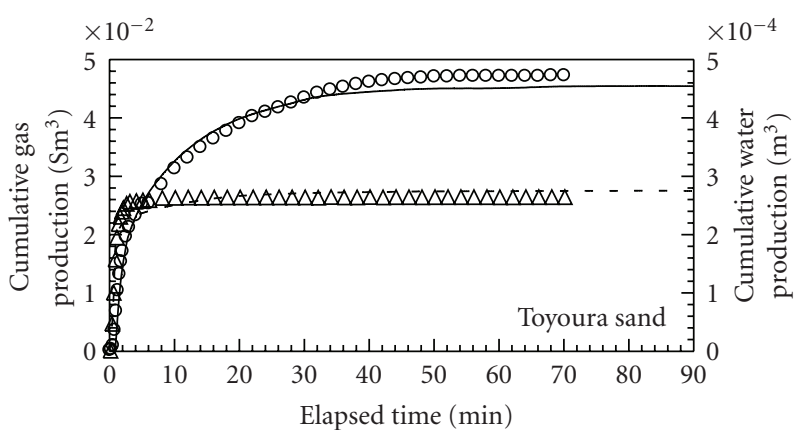

(a)

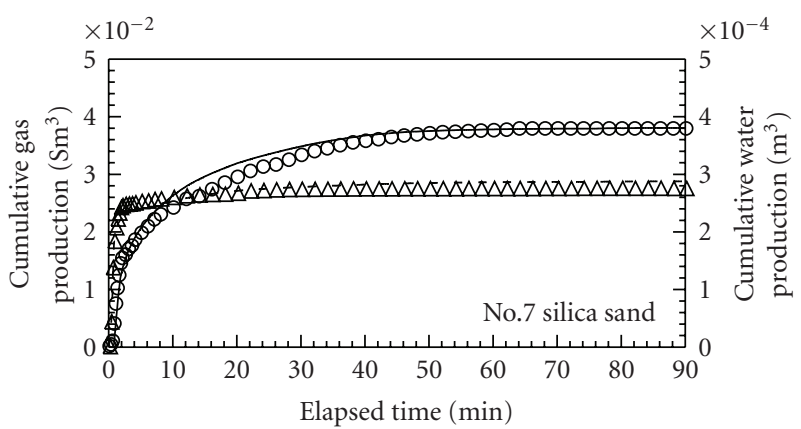

\begin{abstract}
- Cumulative gas production: experimental
- Cumulative gas production: calculation

$\Delta$ Cumulative water production: experimental

- - - Cumulative water production: calculation
\end{abstract}

(b)

FIGURE 12: Comparison of experimental and calculation results for production behaviors of gas and water in the cases of Toyoura sand and No.7 silica sand.

this figure, rapid water discharge at the initial stage and dissociated gas production were similar to the experimental results. However, calculation underestimated the amount of water production $\left(1.8 \times 10^{-4} \mathrm{~m}^{3}\right)$ whereas the experimentally measured value was $2.55 \times 10^{-4} \mathrm{~m}^{3}$. On the other hand, the cumulative gas production was estimated as $4.52 \times$ $10^{-2} \mathrm{Sm}^{3}$, so the calculation result overestimated the amount of gas production by approximately $10 \%$ compared with the experimental one $\left(4.05 \times 10^{-2} \mathrm{Sm}^{3}\right)$. In other words, the estimated amount of gas remaining in the pore space decreased because the water production was underestimated. The reason for the difference between the experiment and calculation is as follows. In the calculation, the pressure of the gas phase is equal to that of the water phase without considering the effect of the capillary pressure. When the Corey model was used for the relative permeability curves, it was impossible to reproduce the observed phenomena in the experiments wherein water was selectively drained under an initial high water saturation condition, and dissociated gas was maintained in the pore space. Therefore, considering the effect of capillary pressure, we optimized the shape of the relative permeability curves so as to yield a water mobility higher than that of gas under the high water saturation condition. For optimization purposes, we introduced the 


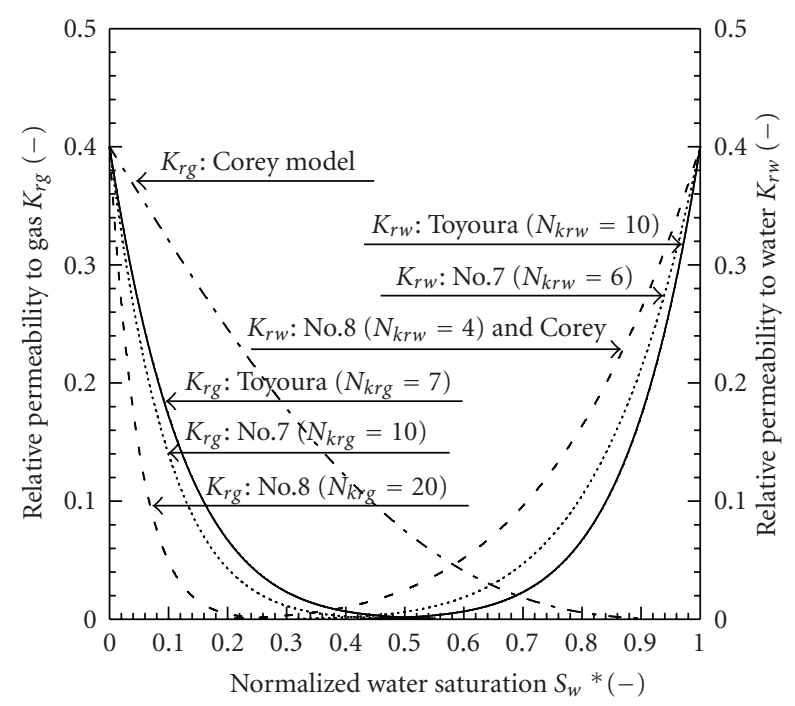

FIGURE 13: Optimized relative permeability curves through series of numerical analysis.

indexes of $N_{k r g}$ and $N_{k r w}$ into the linear relative permeability model as follows:

$$
\begin{aligned}
& k_{r g}=a \cdot\left(1-S_{w}^{*}\right)^{N_{k r g}}, \\
& k_{r w}=b \cdot S_{w}^{* N_{k r w}} .
\end{aligned}
$$

When $N_{k r g}$ is set to a larger value in (22), the water mobility becomes relatively larger than that of gas. On the other hand, the water mobility became smaller under the condition of larger $N_{k r w}$ value. In addition, when $N_{k r w}$ is set to $4, k_{r w}$ is same as that of the Corey model. At $N_{k r g}=2.5, k_{r g}$ overlaps with that of the Corey model. Considering the lower relative permeability to gas in the higher water saturation condition, we set $N_{k r g}$ and $N_{k r w}$ to 20 and 4, respectively. The calculations with these parameters (called extended linear model) are also shown in Figure 11. From this figure, it was found that the calculation could sufficiently reproduce production behavior observed in the experiments containing rapid water production at the initial stage.

Using a similar numerical approach, we conducted history matching of the production behaviors for the cases of Toyoura sand (average sand grain diameter: $200 \mu \mathrm{m}$ ) and No.7 silica sand (average sand grain diameter: $180 \mu \mathrm{m}$ ) as shown in Figure 12. There was excellent agreement between the experimental and simulation results. We used $1.20 \mathrm{~W} /(\mathrm{m} \cdot \mathrm{K})$ (Toyoura) and $1.90 \mathrm{~W} /(\mathrm{m} \cdot \mathrm{K})($ No.7) as the values of thermal conductivity $\lambda c$. In addition, the reduction factors $N_{k r g}$ and $N_{k r w}$ for the relative permeability curves were set at 7 and 10 (Toyoura) and 10 and 6 (No.7), respectively, to reproduce the production behavior during the $\mathrm{MH}$ dissociation by depressurization. Calibrated relative permeability curves obtained through the simulations are shown in Figure 13. Several trends are apparent. As the sand grain diameter became larger, the gas mobility increased under higher water saturation conditions. This indicates that the effect of capillary pressure decreased owing to the increase in the pore diameter. In addition, the shapes of the relative permeability curves reflect the behaviors observed in our experiments, that is, the amount of water production was not so different despite the decrease in the residual water saturation, $S_{w i 0}$, in the case of larger sand grain diameter.

The simulations also confirmed the validity of formulation of irreducible water saturation $S_{w i}$ and residual gas saturation $S_{g r}$, expressed as in (16) to (20), and obtained the optimized shape of relative permeability curves to reproduce production behavior during $\mathrm{MH}$ dissociation by depressurization.

\section{Conclusions}

We conducted an experimental study of the $\mathrm{MH}$ dissociation process by hot-water injection and depressurization and studied the effect of temperature and permeability changes on gas production. On the basis of experimental results, a numerical model for $\mathrm{MH}$ dissociation process in porous media was constructed. In addition, we carried out numerical simulations on laboratory-scale experiments for $\mathrm{MH}$ dissociation and verified the validity of the numerical model. Conclusions are summarized as follows.

(1) It was found that $\mathrm{MH}$ dissociation by hot-water injection consisted of 4 stages: displacement of free methane gas due to water injection, permeability reduction due to additional $\mathrm{MH}$ formation in the downstream zone, actual MH dissociation, and completion of dissociation. MH reformation and growth observed at early times had large effect on dissociation behavior and permeability characteristics.

(2) The decrease of the solid material itself due to $\mathrm{MH}$ dissociation had only a small effect on consolidation. Therefore, we confirmed that the increase in the effective stress at the initial stage of depressurization rather than $\mathrm{MH}$ dissociation was a dominant factor for the consolidation behavior.

(3) On the basis of the experimental results, a numerical model of MH dissociation in a porous media was designed and implemented in a numerical simulator. In our numerical model, we treated the $\mathrm{MH}$ phase as a two-component system by modeling the pore space occupied by MH. One component is derived from irreducible water and is formed so as to cover the surface of a sand grain. The other component is defined as $\mathrm{MH}$ made of movable free water and formed at the central pore space so as to plug the flow path.

(4) On the basis of experimental measurements, absolute permeability, relative permeability, irreducible water saturation, and residual gas saturation with $\mathrm{MH}$ formation were also formulated as a function of $\mathrm{MH}$ saturation, porosity and sand grain diameter and introduced into the numerical model.

(5) Using the developed simulator, we attempted history matching for a laboratory-scale experiment for $\mathrm{MH}$ dissociation by hot-water injection. It was found that 
this simulator developed was able to reproduce temperature change, permeability characteristics, and gas production behavior, associated with both $\mathrm{MH}$ formation and dissociation.

(6) Through history matching for temperature change during $\mathrm{MH}$ dissociation by depressurization, the effect of thermal conductivity on dissociation behavior was discussed. We obtained calibrated values of the apparent thermal conductivity of sediments containing $\mathrm{MH}$. On the basis of production behavior, we optimized the shape of the relative permeability curves so as to reproduce observed water and gas production at both low and high water saturation conditions. The indexes of $N_{k r g}$ and $N_{k r w}$ were introduced into the linear relative permeability model in order to consider the effect of capillary pressure. As a result, the numerical simulations could more accurately reproduce production behavior during the depressurization process .

\section{Symbols}

a: Coefficient for gas relative permeability

$a_{\text {sgr }}$ : Coefficient for calculation of residual gas saturation $(=-3.749 E-05)$

$a_{\text {swi }}$ : Coefficient for calculation of irreducible water saturation $(=3.913 E-06)$

$a_{\phi}$ : Coefficient for calculation of absolute permeability $(=-3.96)$

$b$ : Coefficient for water relative permeability

$b_{\text {sgr }}$ : Coefficient for calculation of residual gas saturation $(=9.764 E-03)$

$b_{s w i}$ : Coefficient for calculation of irreducible water saturation $(=-3.438 E-03)$

$c_{s g r}$ : Coefficient for calculation of residual gas saturation $(=0.980)$

$c_{s w i}$ : Coefficient for calculation of irreducible gas saturation $(=1.048)$

$c_{\phi}$ : Coefficient for calculation of absolute permeability $(=8.55)$

$D_{A}$ : Average sand grain diameter, $\mathrm{m}$

$D_{A T}$ : Average sand grain diameter of Toyoura sand, $\mathrm{m}(=2.000 E-04)$

$d_{\phi r}$ : Coefficient for calculation of absolute permeability $(=-2.86)$

$H_{d}$ : Heat of dissociation, $\mathrm{J} / \mathrm{mol}$

$h_{g}$ : Enthalpy of gas, $\mathrm{J} / \mathrm{mol}$

$h_{w}$ : Enthalpy of water, $\mathrm{J} / \mathrm{mol}$

$K: \quad$ Absolute permeability, $\mathrm{m}^{2}$

$K_{0}$ : Absolute permeability without any $\mathrm{MH}$ formation, $\mathrm{m}^{2}$

$k_{r g}$ : Relative permeability to gas

$k_{r w}$ : Relative permeability to water

$N_{1}$ : Reduction factor for calculation of absolute permeability

$N_{2}$ : Reduction factor for calculation of absolute permeability

$N_{g}$ : Reduction factor for calculation of $S_{g r 00}$
$N_{h}: \quad$ Hydrate number

$N_{k r g}$ : Reduction factor for calculation of $k_{r g}$ in linear relative permeability model

$N_{k r w}$ : Reduction factor for calculation of $k_{r w}$ in linear relative permeability model

$N_{s g r 1}$ : Reduction factor for calculation of $S_{g r 0}$

$N_{s g r 2}$ : Reduction factor for calculation of $S_{g r 0}$

$N_{w}$ : Reduction factor for calculation of $S_{w i 00}$

$N_{\phi}$ : Reduction factor for calculation of absolute permeability

$N_{\phi T}$ : Reduction factor for calculation of absolute permeability $(=5.50)$

$R_{d}$ : Dissociation rate of $\mathrm{MH}, \mathrm{mol} /\left(\mathrm{m}^{3} \cdot \mathrm{s}\right)$

$R_{f}$ : Gas consumption rate due to $\mathrm{MH}$ growth, $\mathrm{mol} /\left(\mathrm{m}^{3} \cdot \mathrm{s}\right)$

$R_{V h w}$ : Volume ratio of $\mathrm{MH}$ to water.

$S_{g}: \quad$ Gas saturation

$S_{g r}: \quad$ Residual gas saturation

$S_{g r 0}$ : Residual gas saturation as function of $\mathrm{MH}$ saturation

$S_{\text {gr } 00}$ : Residual gas saturation as function of average sand grain diameter

$S_{g r T}$ : Residual gas saturation for Toyoura sand without any $\mathrm{MH}$ formation

$S_{h}: \quad$ MH saturation

$S_{w}$ : Water saturation

$S_{w i}: \quad$ Irreducible water saturation

$S_{w i 0}$ : Irreducible water saturation as function of MH saturation

$S_{w i 00}$ : Irreducible water saturation as function of average sand grain diameter

$S_{w i T}$ : Irreducible water saturation for Toyoura sand without any $\mathrm{MH}$ formation

$S_{w}^{*}$ : Normalized water saturation

$T$ : $\quad$ Temperature, $\mathrm{K}$

$T_{0}: \quad$ Standard temperature, $\mathrm{K}(=273.15)$

$\partial t: \quad$ Time step, sec

$U_{g}$ : Internal energy of gas, $\mathrm{J} / \mathrm{mol}$

$U_{h}: \quad$ Internal energy of $\mathrm{MH}, \mathrm{J} / \mathrm{mol}$

$U_{r}: \quad$ Internal energy of rock, $\mathrm{J} / \mathrm{m}^{3}$

$U_{w}$ : Internal energy of water, $\mathrm{J} / \mathrm{mol}$

$\mu_{g}: \quad$ Gas viscosity, $\mathrm{Pa} \cdot \mathrm{s}$

$\mu_{w}: \quad$ Water viscosity, $\mathrm{Pa} \cdot \mathrm{s}$

$\lambda_{c}$ : Apparent heat conductivity of reservoir, $\mathrm{J} /(\mathrm{s} \cdot \mathrm{K})$

$\rho_{g}: \quad$ Mole weight of gas, $\mathrm{mol} / \mathrm{m}^{3}$

$\rho_{h}: \quad$ Mole weight of $\mathrm{MH}, \mathrm{mol} / \mathrm{m}^{3}$

$\rho_{w}$ : Mole weight of $\mathrm{MH}, \mathrm{mol} / \mathrm{m}^{3}$

$\Phi_{g}$ : $\quad$ Flow potential of gas phase, $\mathrm{Pa}$

$\Phi_{w}$ : Flow potential of water phase, $\mathrm{Pa}$

$\phi$ : $\quad$ Porosity

$\phi_{0}: \quad$ Initial porosity

$\phi_{T 0}$ : Initial porosity for Toyoura sand $(=0.412)$.

\section{Acknowledgments}

This work was financially supported by Japan's Methane Hydrate R\&D Program (MH21 Research Consortium) planned by Ministry of Economy, Trade and Industry 
(METI). The authors thank Mr. T. Ohno, Ms. M. Kakumoto, and Ms. T. Nemoto for conducting the experimental and numerical studies of gas hydrates.

\section{References}

[1] Y. F. Makogon, Hydrates of Natural Gas, Pennwell, Tulsa, OK, 1981.

[2] Y. F. Makogon, "Natural gas hydrates: the state of study in the USSR and perspectives for its use," in Proceedings of The $3 r d$ Chemical Congress of North America, Toronto, Canada, June 1988.

[3] Y. Okuda, "Sherbet-like natural gas resources—gas hydrate," Petrotech, vol. 16, pp. 300-305, 1993.

[4] M. Sato and Y. Aoki, "Gas hydrate (IV), geology and prospecting of methane hydrate," The Japan Institute of Energy, vol. 80, pp. 973-995, 2001.

[5] M. Sato, "Gas hydrate (III), distribution of methane hydrate, amount of methane, and resources," The Japan Institute of Energy, vol. 80, pp. 1064-1074, 2001.

[6] M. Kurihara, K. Funatsu, H. Ouch, Y. Masuda, and H. Narita, "Investigation on applicability of methane hydrate production methods to reservoirs with diverse characteristics," in Proceedings of the 5th International Conference on Gas Hydrate, vol. 3, pp. 714-725, Trondheim, Norway, 2005.

[7] A. Masui, H. Haneda, Y. Ogata, and K. Aoki, "Effects of methane hydrate formation on shear strength of synthetic methane hydrate sediments," in Proceedings of The 15th International Offshore and Polar Engineering Conference Seoul, pp. 19-24, Korea, June, 2005.

[8] M. H. Yousif, H. H. Abass, M. S. Selim, and E. D. Sloan, "Experimental and theoretical investigation of methane gas hydrate dissociation in porous media," in Proceedings of the 63rd Annual Technical Conference and Exhibition of the Society of Petroleum Engineers, pp. 571-583, Houston, Tex, USA, 1988.

[9] M. S. Selim and E. D. Sloan, "Hydrate dissociation in sediment," in Proceedings of the 62nd Annual Technical Conference and Exhibition of the Society of Petroleum Engineers, pp. 243 258, Dallas, Tex, USA, 1987.

[10] L. Jeannin, G. Bayi, O. Remard, O. Bonnefoy, and J. M. Herri, "Formation \& dissociation of methane hydrate in sedimentspart II: numarical modelig modeling," in Proceedings of the 4th International Conference on Gas Hydrate, vol. 2, pp. 802-806, Yokohama, Japan, 2002.

[11] G. D. Holder and P. F. Angert, "Simulation gas production from a reservoir containing both gas hydrate and free natural gas," in Proceedings of the 57th Annual Fall Technical Conference and Exhibition of the Society of Petroleum Engineers of AIME, New Orleans, Fla, USA, 1982, SPE 11105.

[12] Y. Masuda, M. Kurihara, H. Ohuchi, and T. Sato, "A field-scale simulation study on gas productivity of formations containing gas hydrates," in Proceedings of the 4th International Conference on Gas Hydrate, vol. 1, pp. 40-46, Yokohama, Japan, 2002.

[13] Y. Sakamoto, T. Komai, T. Kawamura, H. Minagawa, N. Tenma, and T. Yamaguchi, "Laboratory-scale experiment of methane hydrate dissociation by hot-water injection and numerical analysis for permeability estimation in reservoirpart 1: numerical study for estimation of permeability in methane hydrate reservoir," International Journal of Offshore and Polar Engineering, vol. 17, no. 1, pp. 47-56, 2007.

[14] Y. Sakamoto, T. Komai, H. Haneda, T. Kawamura, N. Tenma, and T. Yamaguchi, "Experimental study on modification of permeability in a methane hydrate reservoir and gas production behavior by the simultaneous injection of nitrogen and hot water," in Proceedings of the 5th International Conference on Gas Hydrate, vol. 3, pp. 866-874, Trondheim, Norway, 2005.

[15] Y. Sakamoto, T. Komai, Y. Kawabe, and T. Yamaguchi, "Properties of multiphase flow in marine sediments with gas hydrate," in Proceedings of the 5th ISOPE Ocean Mining Symposium, pp. 171-175, Tsukuba, Japan, 2003.

[16] Y. Sakamoto, M. Shimokawara, K. Ohga, et al., "Numerical study on dissociation of methane hydrate and gas production behavior in laboratory-scale experiments for depressurization-part 3: numerical study on estimation of permeability in methane hydrate reservoir," The International Society of Offshore and Polar Engineers, vol. 19, pp. 124-134, 2009.

[17] Y. Sakamoto, T. Komai, T. Kawamura, H. Minagawa, N. Tenma, and T. Yamaguchi, "Modification of permeability model and history matching of laboratory-scale experiment for dissociation process of methane hydrate-part 2: numerical study for estimation of permeability in methane hydrate reservoir," International Journal of Offshore and Polar Engineering, vol. 17, no. 1, pp. 57-66, 2007.

[18] Y. Sakamoto, M. Shimokawara, K. Ohga, et al., "Field scale simulation for consolidation and gas production behavior during depressurization process of methane hydrate in marine sediments," in Proceedings of Offshore Technology Conference, Houston, Tex, USA, 2008, OTC19283.

[19] G. Zyvoloski, Z. Dash, and S. Kelkar, "FEHMN 1.0 finite element heat and mass transfer code," Tech. Rep. LA-12062MS, Rev.1, Los Alamos National Laboratory, Los Alamos, Calif, USA, 1992.

[20] G. Zyvoloski, "FEHM: a control volume finite element code for simulating subsurface multi-phase multi-fluid heat and mass transfer," Tech. Rep. LAUR-07-3359, Los Alamos National Laboratory, Los Alamos, Calif, USA, 2007.

[21] R. J. Pawar, G. A. Zyvoloski, N. Tenma, Y. Sakamoto, and T. Komai, "Numerical simulation of laboratory experiments on methane hydrate dissociation," in Proceedings of the 15th International Offshore and Polar Engineering Conference, vol. 1, pp. 379-385, Seoul, South Korea, 2005.

[22] M. Kurihara, A. Sato, H. Ouchi, H. Narita, and Y. Masuda, "Prediction of gas productivity from Eastern Nankai Trough methane-hydrate reservoirs," in Proceedings of Offshore Technology Conference, Houston, Tex, USA, 2008, OTC19382.

[23] Y. Yamamoto, T. Kawamura, M. Ohtake, et al., "Measurement of thermal conductivity of artificial hydrate sediment sample," in Proceedings of the 14th International Offshore and Polar Engineering Conference, pp. 36-40, Toulon, France, 2004.

[24] Y. Yamamoto, T. Kawamura, M. Ohtake, et al., "Measurement of thermal conductivity of hydrate sediment sample," in Proceedings of the 15th International Offshore and Polar Engineering Conference, vol. 1, pp. 341-345, Seoul, South Korea, 2005. 

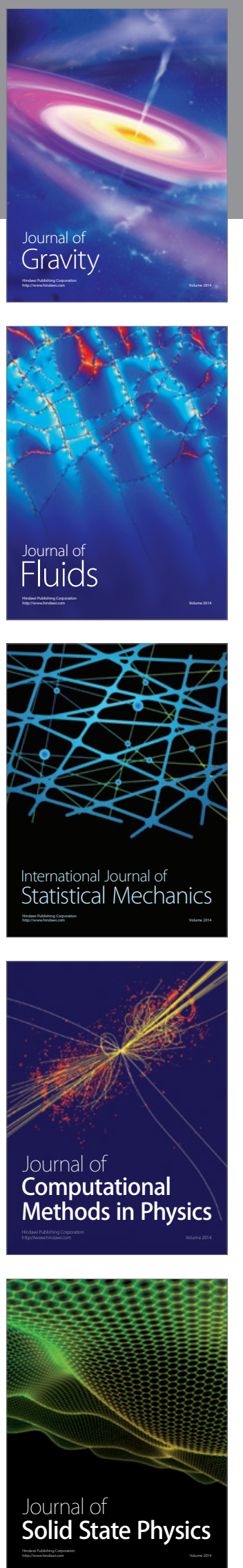

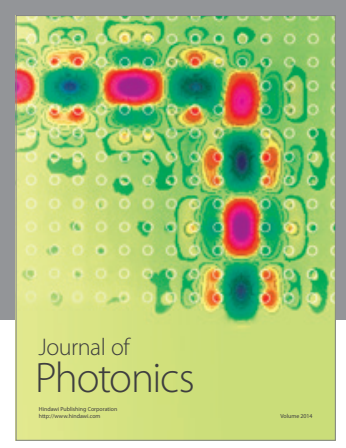

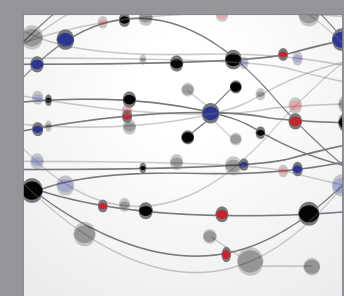

The Scientific World Journal
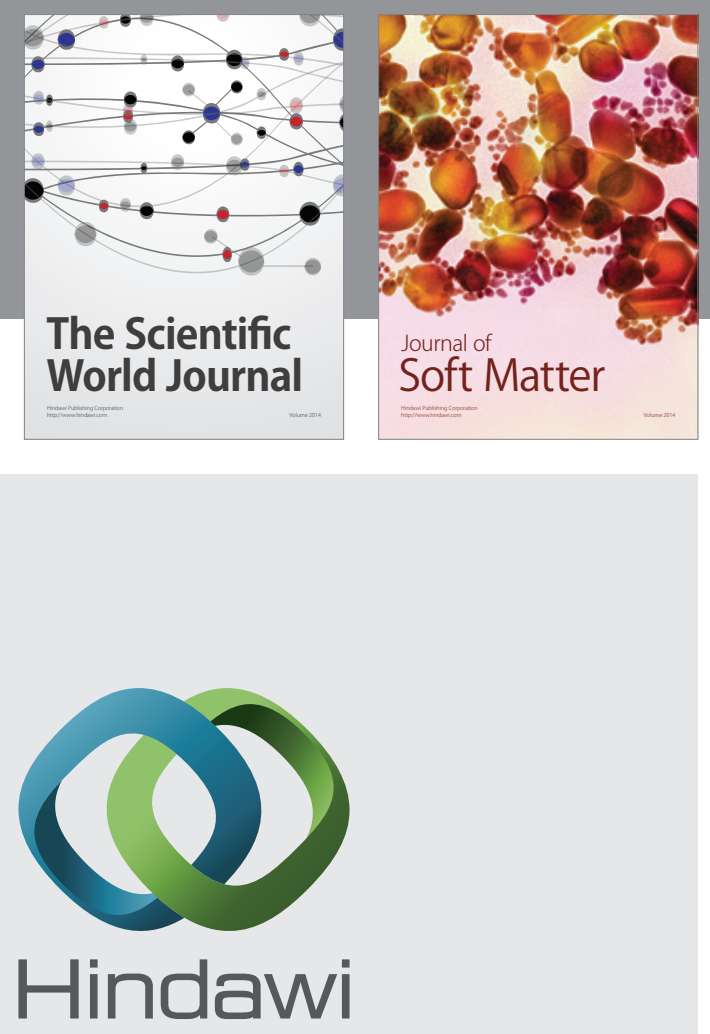

Submit your manuscripts at

http://www.hindawi.com
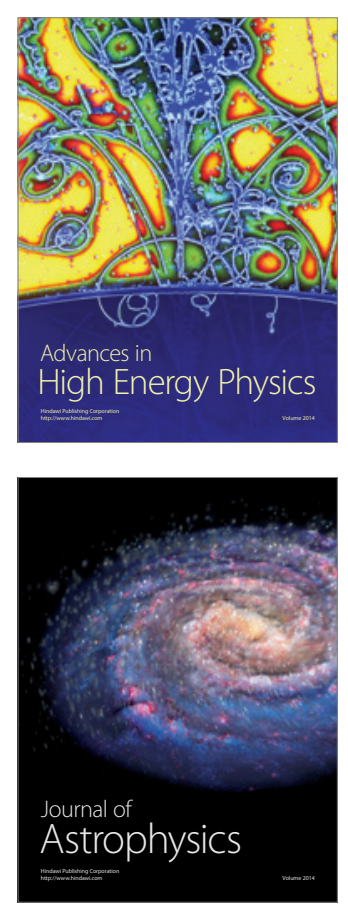
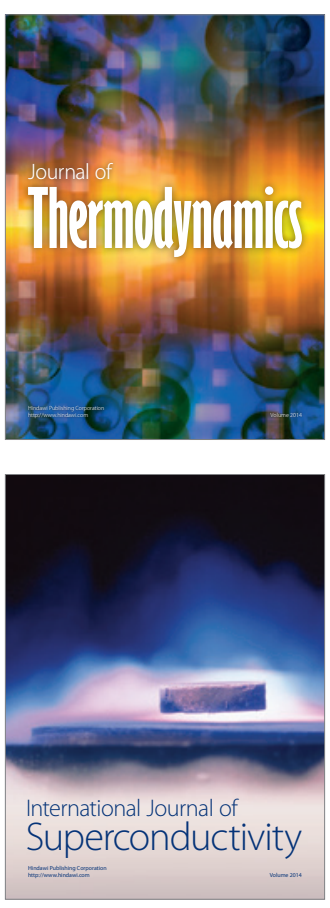
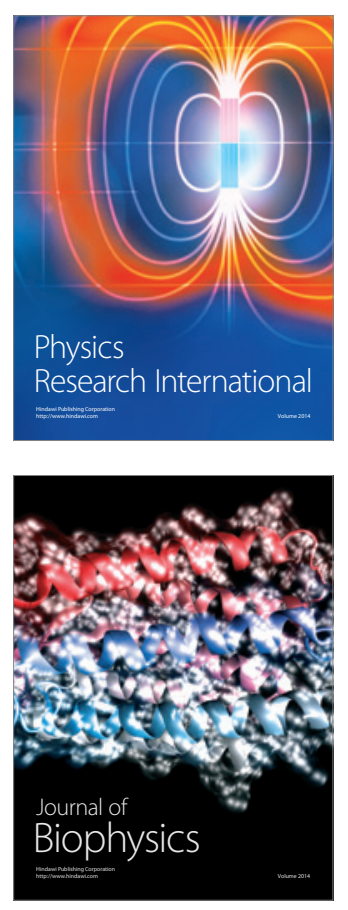
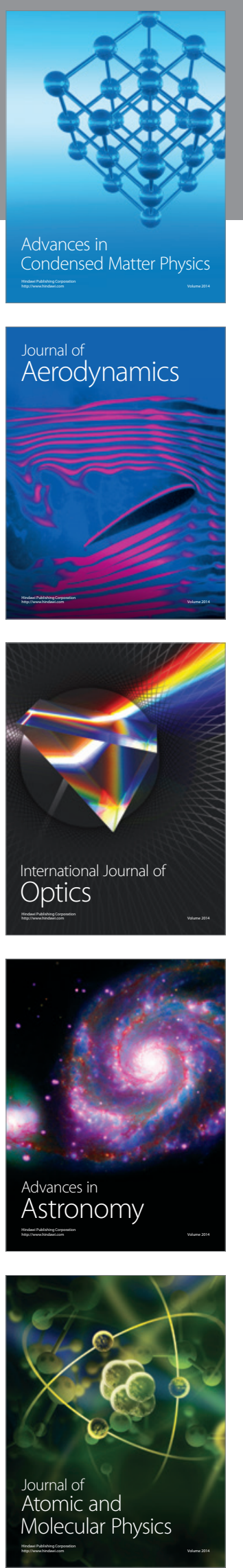